\title{
To Solve the Game Study of Financing Difficulty in the Development of Rural Revitalization Strategy
}

\author{
Dong Xiaohong \\ School of finance, Harbin University of commerce, University Street, Harbin, China \\ 33587015@qq.com
}

Keywords: rural revitalization strategy; Rural financial institutions; Mixed strategy Nash equilibrium; Game

\begin{abstract}
Through the game analysis of the behavior between rural financial institutions and local governments, the mixed strategy Nash equilibrium formed by rural financial institutions and government was obtained. In the development of rural revitalization strategy, the rural credit evaluation system should be established as soon as possible, so as to reduce the cost of identifying user information and reduce the non-performing repayment rate of rural financial institutions. The best solution was which government incentives was given priority, in order to restraint policy was complementary, only in this way could make the government and the rural financial institutions wouldl eventually go win-win cooperation, which solved the problem of rural financing difficulties.
\end{abstract}

\section{Introduction}

The development of rural finance in China has restricted the growth of rural economy. Only the development of rural finance was coordinated with the growth of rural economy, and the development of rural finance would promote the growth of rural economy. Rural financial institutions (including policy-based finance, commercial finance and cooperative finance) were the main means of rural financing, mainly serving agriculture and farmers. At the same time, the local government was not the money directly provider of rural financial system, but it could use its administrative power to rural financial system incalculable impact the supply of funds. which this makes rural financial institutions and local governments had mutual dependence and mutual restraint. Game so as to make the rural financial institutions and local government, between the game, this shows was that some of the local government institutional constraints exist unsatisfactory place, at the same time, the game also could make the problem more prominent, and thus more conducive to solve the problem. This paper studied the complicated game relationship between rural financial institutions and local governments from the perspective of game, and then discusses the causes and countermeasures of rural financing difficulties in rural revitalization strategy development.

\section{Model design}

\subsection{The basic assumptions}

Hypothesis 1 was that under the target of local government to solve the problem of rural financing difficulties as soon as possible so that we could promote the development of rural finance and make the development of rural finance and rural economic coordinated growth. The goal of the organization is to maximize its own revenue.

Hypothesis 2 was that under the incentive policies of local governments, the rural financial institutions (hereinafter referred to as the institutions) could actively cooperate with local governments.

The work of the departmen twas which the strategy of active support for agriculture was rewarded as $\mathrm{r}$, and the organization pays for the policy of active support.

For $\mathrm{C}$, the cost of agency due to adopting the tactics of positive support to get the corresponding 
earnings of r. under the local government to implement "constraint" policy, to cooperate with the guidance of the local government department, which was not to give a fine to support agriculture negative behavior for $\mathrm{F}$.

Hypothesis 3 was that the benefits obtained by the local governments in achieving their goals include economic and social benefits, namely, the utility of achieving the goal was G. Different strategies had different impacts on local government goals. The degree $\alpha \quad(0 \leq \alpha<1)$ of influence under the incentive policy, $\beta(0 \leq \beta<1)$ was the degree of influence under the constraint policy.

Hypothesis 4 was that institutions choosing active farmers was $\mathrm{P}(0 \leq P \leq 1)$, the probability of negative support is $1-\mathrm{P}$, and the mixed strategy of the institution was $P_{1}=(p, 1-p)$. The probability of local government implementing incentive policy was $q(0 \leq q \leq 1)$, and the implementation of the constraint policy. The ratewas1-q , the policy mix strategy was $p_{2}=(q, 1-q)$.

Through the above assumptions, we could obtain the respective benefits obtained by the choice strategies of the two parties: when the local government implements the incentive policy, if the agency chooses the active support strategy, the profit would be $r+R-C$,Local government revenue $G-r$; If the agency choosed the negative support strategy, the profit would be 0 and the local government revenue would be $\alpha G$. When the local government implements the restriction policy, if the organization choosed the active support strategy, its income was $R-C$, the local government revenue was $G$; If the agency chooses the negative support strategy, its revenue would be $-\mathrm{F}$ and local government revenue would be $\beta G+F$. The benefit matrix was shown in table 1 . The equilibrium solution can be obtained by using the mixed strategy Nash equilibrium.

Table 1 Benefits Matrix of Institutions and local Governments

\begin{tabular}{c|cc}
\hline Local government & Incentive policy & constraint policy \\
Rural financial institutions & & \\
\hline Actively & $r+R-C, G-r$ & $R-C, G$ \\
Negative & $0, \alpha G$ & $-F, \beta G+F$ \\
\hline
\end{tabular}

\subsection{Game analysis of local government and institutional behavior}

The definition of mixed strategy Nash equilibrium

The standard game in $\mathrm{n}$ game players was: $G=\left\{S_{1}, S_{2}, \cdots, S_{n} ; u_{1}, u_{2}, \cdots, u_{n}\right\}$, So if you were dealing with every game. $i(i=1,2,3 \cdots, n) p_{i}^{*}$ was a mixed strategy combination for other players $p_{i}^{*}=\left(p_{1}^{*}, p_{2}^{*}, \cdots p_{i-1}^{*}, p_{i+1}^{*}, \cdots p_{n}^{*}\right)$ was optimal reaction.

$$
\begin{aligned}
& u_{i}^{e}\left(p_{1}^{*}, p_{2}^{*}, \cdots p_{i-1}^{*}, p_{i}^{*}, p_{i+1}^{*}, \cdots p_{n}^{*}\right) \geq u_{i}^{e}\left(p_{1}^{*}, p_{2}^{*}, \cdots p_{i-1}^{*}, p_{i j}, p_{i+1}^{*}, \cdots p_{n}^{*}\right) \quad \forall p_{i} \in P_{i} \quad j=1,2, \cdots, k \\
& \text { so }\left(p_{1}^{*}, p_{2}^{*}, \cdots p_{i-1}^{*}, p_{i}^{*}, p_{i+1}^{*}, \cdots p_{n}^{*}\right) \text { was a Nash equilibrium. }
\end{aligned}
$$

\subsection{To solve the mixed strategy nash equilibrium of local government and institution}

Through the above assumptions and definitions, the expected profit functions of the institutions and local governments were:

$$
\begin{gathered}
u_{1}^{e}\left(p_{i}, p_{2}\right)=p q(R+r-c)+p(1-q)(R-c)-F(1-p)(1-q) \\
=p q r+p R-p c-F+q F+p F-p q F \\
u_{2}^{e}\left(p_{i}, p_{2}\right)=p q(\alpha G-r)+p q \alpha G+(1-p) q \beta G+(1-p)(1-q)(\beta G+F) \\
=p q \alpha G-p q r+q G+\beta G-p \beta G-q \beta G+p q \beta G+F-p F-q F+p q F
\end{gathered}
$$

We know from the above assumptions and definitions: 


$$
p^{*}=\left(p_{1}^{*}, p_{2}^{*}\right)
$$

was a mixed strategy Nash equilibrium, according to the definition:

$$
\begin{aligned}
& u_{1}^{e}\left(p_{i}^{*}, p_{2}^{*}\right) \geq u_{1}^{e}\left(p_{i}, p_{2}^{*}\right) \\
& u_{2}^{e}\left(p_{i}^{*}, p_{2}^{*}\right) \geq u_{2}^{e}\left(p_{i}, p_{2}^{*}\right)
\end{aligned}
$$

By solving optimization problems, namely:

$$
\begin{gathered}
\max _{p_{1} \in P_{1}} u_{1}^{e}\left(p_{1}, p_{2}^{*}\right)=\max _{0 \leq p \leq 1} p q^{*} r+p R-p c-F+q^{*} F+p F-p q^{*} F \sqsubset \\
\max _{p_{2} \in P_{2}} u_{1}^{e}\left(p_{1}^{*}, p_{2}\right)=\max _{0 \leq q \leq 1}(p q \alpha G-p q r+q G+\beta G-p \beta G \\
-q \beta G+p q \beta G+F-p F-q F+p q F)
\end{gathered}
$$

Take the first derivative of the above equation respectively and make it equal to 0 .

$$
\begin{aligned}
& \frac{\partial u_{1}^{e}\left(p_{1}, p_{2}^{*}\right)}{\partial p}=q * r+r-c+F-q * F=0 \Rightarrow q *=\frac{c-R-F}{r-F} \\
& \frac{\partial u_{2}^{e}\left(p_{1}^{*}, p_{2}\right)}{\partial q}= p q \alpha G-p q r+q G+\beta G-p \beta G \\
&-q \beta G+p q \beta G+F-p F-q F+p q F=0
\end{aligned}
$$

The Nash equilibrium of the mixed strategy was:

$$
\left(p_{1}^{*}, p_{2}^{*}\right)=\left\{\left(\frac{F+\beta G-G}{(\alpha+\beta) G+F-r}, \frac{\alpha G-r+G}{(\alpha+\beta) G+F-r}\right),\left(\frac{c-R-F}{r-F}, \frac{r-c+R}{r-F}\right)\right\}
$$

\subsection{Mixed strategy Nash equilibrium analysis}

The probability that the agency adopts active supporting strategy was $\frac{F+\beta G-G}{(\alpha+\beta) G+F-r}$, The probability of adopting a negative support strategy was $\frac{\alpha G-r+G}{(\alpha+\beta) G+F-r}$,In other words, the organization would choose two strategies based on their respective probabilities. When other factors didn't change, $\mathrm{F}$ increased, they made $\frac{F+\beta G-G}{(\alpha+\beta) G+F-r}$ Increased, at the same time, $\frac{\alpha G-r+G}{(\alpha+\beta) G+F-r}$ was decrease, namely: When the policy issued by the local government, to cooperate with the local government to guide the work of agencies to heavy penalties, institutions took the proportion of positive policies for supporting agriculture should be greater than the proportion of take negative policies for supporting agriculture. When there was a certain amount of punishment, in such a situation, the agency's active support strategy would maximize its own interests. At the same time. When other factors are constant,r was Increased, which would make $\frac{F}{(\alpha+\beta) G+F-r}$ Increase, at the same time, $\frac{(\alpha+\beta) G-r}{(\alpha+\beta) G+F-r}$ reduced, i.e., when the policy issued by the local government, give awards to cooperate to guide the work of local government organizations, institutions took the proportion of positive policies for supporting agriculture should be greater than the proportion of take negative policies for supporting agriculture. And $r$ was the 
larger the increase, the greater the incentive for the organization to take active support for agriculture, because it was the best strategy for the organization to choose active farmers. The probability of local governments implementing incentive policies was $\frac{c-R-F}{r-F}$, At the same time, $r>c>F$ Would make $\frac{c-R-F}{r-F}$ Meaningful, which $\mathrm{R}$ usually was small relatively $\mathrm{C}$, the agency would not actively support agriculture, one of the reasons for the optimal strategy was to maximize their own interests, so the most urgent task was to establish rural credit evaluation system as soon as possible, reduce the cost of agency to identify the user information, and thus would reduce the bad repayment rates of institutions, the institutions due to poor repayment caused by accumulation of bad assets was higher, more serious loss of the institution, as time passes could make the organization to support agriculture strategy to be negative their optimal strategy.The probability of the local government implementing the constraint policy was $\frac{r-c+R}{r-F}$, when it met $q>\frac{c-R-F}{r-F}$ Local governments would choose incentives; when it met $q<\frac{c-R-F}{r-F}$, local governments would choose to restrict policy; when it met $q=\frac{c-R-F}{r-F}$, local governments would choose a hybrid strategy.

\section{Conclusion}

From the above analysis, we could see that the incentive system for local government incentive policies should be the optimal strategy for rational rural financial institutions. Because of the increased incentive, this was undoubtedly the benefit of rural financial institutions, which was also the interest target pursued by the rural financial institutions. So local governments to establish an effective incentive system, with preferential policies, such as the way to make rural financial institutions were willing to actively support agriculture rather than doing nothing, take negative support agriculture policy, which made the rural financial institutions were actively support agriculture benefit. To solve the problem of rural revitalization strategy in the development of financing, as soon as possible to establish rural credit evaluation system, review to reduce agency cost, and thus would reduce the bad repayment rates of institutions, which would increase the income of the rural financial institutions. At the same time, local governments can truly did not interfere in the business of rural financial institutions, but they should bear some of the supervisory responsibilities and properly use the rights and obligations of local governments.

The punishment system in the restraint mechanism of the local government was also the optimal strategy for the rational rural financial institutions to adopt the strategy of actively supporting agriculture. This would also hurt the interests of rural financial institutions because of the increased penalties. We knew from the above analysis, the local government's constraint mechanism in the system of punishment, which would remain part of the proportion of rural financial institutions to take negative support agriculture policy, then the later punishment did not reduce the loss that had been done, which also could be to have the effect of temporary relief. The best solution was for local government incentives, constraints policy as the auxiliary pole, only in this way would make the local government and rural financial institutions would eventually go win-win cooperation, so really solve the problem of rural financing difficulties.

\section{Acknowledgements}

This paper is the periodical achievement of the general project of the national social science foundation (17BJY119), Ministry of education humanities and social science research project 
(16YJA790067) and the social science philosophy project of heilongjiang province (16JYE01).

\section{References}

[1] Cai Siping. (2015) The logic basis of the reconstruction of rural financial organization system from the perspective of interest gaming function. Financial theory and practice, 01,2-10.

[2] Zhang Songying., (2016) Thoughts on the sustainable development of rural financial markets. China securities futures, 09,35-37.

[3] Wang Yuan, (2016) information processing, game participation and rural financial services intermediaries [J], financial research,10,41-46.

[4] Chen Hanming, (2014) from the perspective of game theory, rural financial reform, journal of central China agricultural university (social science edition),2,31-35.

[5] Kuang Mei, Zhao Ke, (2013) Game analysis of rural credit relations in China. Journal of central university of finance and economics,7,37-43.

[6] Liu Renwu. (2010) Financial problems in new rural construction. China financial press, 100-112. [7] Jinhe Hui, Qian Ying, - yi WEINGAST. (2015) BERRY Regional Decentralization and Fiscal Incentives: Federalism, Chinese Style, Journal of Public Economics, 89, 719-1742.

[8] MONTETCHRISTIAN, SERRA DANIEL. (2013) Game Theory and Economics, Houndmills: Palgrave Macmillan,48-50.

[9] Kenneth N. Daniels, (2010) Demissew Diro Ejara, Jayaraman Vijayakumar. Debt Maturity, Credit Risk, and Information Asymmetry: The Case of Municipal Bonds, Financial Review, 3,603626

[10] Luiz de Mello. (2014) Fiscal Decentralization and Intergovernmental Fiscal Relations: A Cross-Country Analysi, World Development, 2,261-268

[11] Liyin Shen, Andrew Platten, X. P. Deng. (2016) Role of Public Private Partnerships to manage risks in public sector projects, International Journal of Project Management, 7,587-594.

[12] Dong Xiaohong. (2012) Based on VAR Empirical Research of Rural Financial Development and Economic Growth in China, 3rd International Conference on E-Business and E-Government, 8,125-129.

[13] Berger., (2011) Anudell Gesmall Business Gredit Availability and RelationshiP Lending: T heIm Portanee of Bank Organizational Structure, Eeonomic Joumal, 112,32-54.

[14] Lu Y Z, (2014) Endogenous timing in a mixed oligopoly consisting of a single public firm and foreign competitors, Economics Bulletin, 12, 1 - 7.

[15] Yang, X. H, Luo, Y. F, Wu, H. Q, (2015) On the compariso n o f price and quantity competition under endo genous t iming, Resear ch in Economics, 63, 55- 61.

[16] Tasnadi., (2015) A. Price vs quantity in oligopoly games, International Journal of Industrial organization, 24,541- 554.

[17] Yang jie, (2015) in Kenyon. Empirical research on the ownership structure and its influence of village level collective economic organizations in China -- based on empirical evidence at the village level in Beijing, Chinese soft science, 3127-13.

[18] Wang Changyun, Zhongteng Zheng china chem. (2014) Does financial marketization improve farmers' credit availability? -- empirical research based on household survey, Economic research, 10 33-44.

[19] Mao Pehua, Xu Ji, He Xiaodan, Zhou Yahong., (2015) The circulation of farmland management rights and the improvement of farmers' labor productivity: theory and evidence, Economic research, 11,161-176.

[20] Ni Guohua, Cai Fang. (2015) How much farmland do farmers need? Economic research, 3, 159-171. 